DOI: 10.20472/IAC.2018.044.036

MIHAI NIȚOI

Institute for World Economy, Romanian Academy, Romania

CRISTIAN VALERIU STANCIU

Department of Finance, University of Craiova, Romania

CRISTI SPULBĂR

Department of Finance, University of Craiova, Romania

\title{
CO-MOVEMENT BETWEEN STOCK MARKETS AND EXCHANGE RATES IN CENTRAL AND EASTERN EUROPE
}

\begin{abstract}
:
Generally, the exchange rate and the stock market have been some of the most studied areas in finance. Furthermore, the nexus between the two assets has been reviewed in a significant number of studies, but with conflicting results. The flow oriented model posits a positive link between exchange rate and stock market (Dornbusch and Fischer, 1980), the portfolio based model assume a negative relationship between exchange rate and stock market, and the monetary model indicates a weaker or no link between the two assets (Branson and Henderson, 1985; Frankel, 1983).

This article studies the nexus between exchange rates and stock markets in four countries in Central and Eastern Europe (Czech Republic, Hungary, Poland, and Romania) over the period from 1999 to 2016. In our opinion, our contribution to the literature is manifold. Firstly, even if the papers that analyse the correlation between exchange rates and stock markets are numerous (Lee et al., 2011; Lestano and Kuper, 2015; Caporale et al., 2014; Moore and Wang, 2014; Lin, 2012; Lee et al. 2014), surprisingly, to our knowledge, for Central and Eastern European countries there is a scarce literature in this area. Secondly, we document the time varying correlation in both normal period and crisis period, allowing us to investigate the differences. Thirdly, compared with other studies, we employ a DCC-MIDAS model that enables the extraction of short- and long-term correlation series. Generally, other DCC models estimate only a short-run component for the correlation. Therefore, solely by averaging the high-frequency component, we may obtain a low-frequency component. The DCC-MIDAS model obviates this disadvantage.

Our findings are summarized as follows. Firstly, we find significant differences between the four countries. Secondly, we notice an increased variance in terms of time varying correlation between stock market and exchange rate. Therefore, we cannot identify a clear pattern for the correlation. Thirdly, during the most severe crisis episodes, we see an increased correlation, indicating some signs of contagion and lower portfolio diversification.
\end{abstract}

\section{Keywords:}

DCC-MIDAS, emerging stock markets, exchange rate, contagion, financial crisis

JEL Classification: F31, G01, G15 